\title{
Spreading human factors expertise in healthcare: untangling the knots in people and systems
}

\section{Ken Catchpole}

\section{Correspondence to}

Dr Ken Catchpole,

Surgical Safety and Human

Factors Research, Cedars-Sinai

Medical Center, Suite 302,

8797 Beverly Blvd, Los Angeles,

CA 90048, USA;

ken.catchpole@cshs.org

Received 26 March 2013 Accepted 26 March 2013

Published Online First

16 April 2013

\section{CLinked}

- http://dx.doi.org/10.1136/ bmjqs-2012-001450
To cite: Catchpole K. BMJ Qual Saf 2013;22:793-797.

\section{INTRODUCTION}

Human factors (HF) is a term many involved in healthcare delivery are now familiar with, even though a decade ago most had never heard of the concept. The majority of clinicians and healthcare improvement specialists have learned of HF through a particular branch of practice that derived from aviation and arose from the need to address error, teamwork and communication issues. This behavioural safety approach, while entirely legitimate and increasingly well evidenced, is limited. Yet, it has dominated perceptions of what constitutes HF and shaped the application of HF principles in healthcare. Frequently espoused by well meaning clinicians and aviators, rather than academically qualified HF professionals, it has led to misunderstandings about the range of approaches, knowledge, science and techniques that can be applied from the field of HF to address patient safety and quality of care problems.

In this issue, Russ et $a l^{1}$ seek to redress some of the consequences of this misappropriation. They articulate the problems succinctly and expand on earlier calls ${ }^{2}{ }^{3}$ for greater integration of HF expertise in healthcare. Repeatedly encountering recurrent misunderstandings and misuse of $\mathrm{HF}$ undoubtedly concerns academic experts. However, rather than feeling frustration over the 'fictions' discussed by Russ et al, ${ }^{1}$ HF professionals should be encouraged by the tremendous progress made in recent years-from a state in which clinicians had little exposure to HF work, and even fewer saw its value, to widespread acknowledgement of the value of human-centred systems thinking in healthcare.

Yet, the origins of the misunderstandings of HF discussed by Russ et $a l^{1}$ warrant reflection, as they may signal deeper problems in healthcare and the ways in which HF experts have worked in healthcare. One simple reason for misunderstandings about HF arising so commonly in healthcare may be that the spread of HF principles and activities in healthcare has involved many nonexperts. A second, deeper source of the misunderstandings of HF in healthcare relates to the dominance of particular HF practices largely as applied to aviation. The remainder of this commentary explores this history of the importation of aviation-focused HF into healthcare.

In the context of the discussion by Russ et $a l^{1}$ about fictions and misunderstandings about HF among non-experts, this editorial aims to move beyond lines of demarcation about what does or does not constitute legitimate HF principles or practices, with the intention of creating a more bidirectional discussion between HF experts and clinicians about how to more productively advance an agenda that many of us regard as fundamentally important for the future of healthcare.

Before proceeding further, though, let me state that my beliefs in the value of HF expertise and human-centred systems design are highly partisan. I value tremendously engaging the clinical community in understanding human fallibility and applying high-quality $\mathrm{HF}$ practices and behavioural safety to improve healthcare systems. In part as an apology to those clinicians and HF practitioners whom I may have offended in attempting to achieve these goals, this editorial became a personal and professional imperative. Clinicians and HF professionals should be collectively proud of what has already been achieved. But, harnessing the true potential of $\mathrm{HF}$ in healthcare demands that we address the problematic ways in which their principles and techniques have been applied in healthcare to date and the ways in which HF professionals have tended to work with clinicians. 


\section{THE AVIATION MODEL: A DOUBLE-EDGED SWORD}

Healthcare safety analogies have been dominated by the aviation model. ${ }^{4} 5$ Analogies to aviation helped clinicians understand the principles of systems safety and error causation. They also stimulated reflection on hitherto under-acknowledged systemic vulnerabilities that contribute to technical failures and poor outcomes, hopefully supplanting the traditional view that individual clinicians wholly bear responsibility for all patient outcomes. Comparisons with aviation thus underpinned calls to reduce the culture of blame, and they provided a goal for safety that might one day be achieved in healthcare. Comparisons with other industries could have achieved these goals too. Nuclear power, the military and industries that use HF techniques have also been discussed in healthcare, but aviation is an industry with which we all have at least some familiarity. Indeed, aviation is probably where HF principles have been most successfully applied, and where the profession was born in the 1940s. ${ }^{6}$ About 40 years later, Crew Resource Management (CRM) training (often termed 'HF training') arose to address behavioural safety, after an ecosystem of system-level HF interventions (table 1) had already been established. However, in healthcare, CRM was among the first, and has been by far the most dominant HF paradigm. ${ }^{5}$

The translation of CRM training for healthcare has delivered better perceived teamwork and positive perceptual changes, ${ }^{7-12}$ better observed team skills, ${ }^{7} 91213$ better satisfaction with care, ${ }^{7}$ improved compliance with briefings, ${ }^{14}$ better processes, ${ }^{15-17}$ reduced error rates 91218 and better organisational perceptions that help sustained institutional change. ${ }^{8-10} 16$ Indeed, the behavioural safety approach has received more scrutiny in healthcare than in any other industry, including aviation, amplifying the evidence base and raising the awareness and skills of individual clinicians. It also led to the development of a range of tools to assist in improving teamwork and communication that go far beyond the limited scope of such training. ${ }^{19-22}$ The promise of relatively simple behavioural solutions to safety problems leads to courses developed not by trained HF professionals, but by clinicians or aviators, based purely on the limited CRM models, yet erroneously claiming to teach HF. This development has made many academically qualified HF practitioners uneasy because of the lack of broader approaches to systems theory, HF integration, human-centred design or HF analysis techniques within these courses. An early study illustrates this tension between the academic and clinical models of HF training:

\begin{abstract}
we had the opportunity to note the views of James Reason ... on many occasions he appeared to find the content of the course somewhat questionable and in some circumstances inaccurate ... On several occasions he appeared quite agitated and perplexed at the way in which the course often 'misses the point' ... [at lunchtime] he decided to stop watching. ${ }^{23}$
\end{abstract}

In 2011 the British Medical Journal published a head-to-head discussion asking the question: 'Have we gone too far in translating ideas from aviation to patient safety?. ${ }^{24} 25$ To a HF practitioner, this discussion seemed moot, highlighting the erroneous view that aviation provided the 'principle', rather than one of many exemplar applications of deeper, scientifically based principles of HF. These same principles have found application in the design of nuclear power stations, military equipment and a wide range of consumer products, including mobile phones, software, and even toothbrushes, chairs and kettles. ${ }^{26}$ In this broader view of HF, training counts as a limited approach to improving safety-just one aspect of a wider systems approach to equipment, task, environment and organisational

Table 1 Contrasts between aviation and healthcare

\begin{tabular}{|c|c|c|}
\hline & Aviation examples ${ }^{29}$ & Healthcare examples ${ }^{30}$ \\
\hline Equipment design & $\begin{array}{l}\text { A cockpit is designed to minimise perceptual and control } \\
\text { errors, }{ }^{31} \text { security systems have been developed to reduce } \\
\text { operator fatigue and boredom and enhance training } \\
\text { opportunities }^{32}\end{array}$ & $\begin{array}{l}\text { Equipment predisposes to control }{ }^{33} \text { and perceptual errors, } \\
\text { often poorly maintained, with significant gaps in engineering for }^{34} \\
\text { safety }^{35}\end{array}$ \\
\hline Task design & $\begin{array}{l}\text { Design based on a thorough understanding of what is needed } \\
\text { to get an aircraft safely from } A \text { to } B^{36}\end{array}$ & $\begin{array}{l}\text { Lack of standardisation, }{ }^{37} \text { professional autonomy, differences } \\
\text { between practice settings, and differing prioritisations of } \\
\text { competing goals gave rise to widespread variation in individual } \\
\text { behaviours and institutional protocols, }{ }^{38} \text { making task definition a } \\
\text { challenge }\end{array}$ \\
\hline $\begin{array}{l}\text { Communications and } \\
\text { teamwork }\end{array}$ & $\begin{array}{l}\text { Structured communications are embedded within tasks that } \\
\text { are well defined, trained and practiced } \\
39\end{array}$ & $\begin{array}{l}\text { Safety communications }{ }^{40} \text { and tasks }{ }^{41} \text { are highly variable and } \\
\text { tasks can be intermittently performed }\end{array}$ \\
\hline Selection and training & $\begin{array}{l}\text { Specific scientific approach, }{ }^{42} \text { including simulation and } \\
\text { recurrent training }\end{array}$ & $\begin{array}{l}\text { Training follows the apprentice model, with little attention to } \\
\text { rigorously establishing which skills are essential or even for } \\
\text { evaluating the degree to which these skills have been } \\
\text { successfully acquired }\end{array}$ \\
\hline $\begin{array}{l}\text { Incident reporting } \\
\text { systems }\end{array}$ & $\begin{array}{l}\text { Encouraged reporting behaviours. }{ }^{44} \text { 'Black box' flight } \\
\text { recorders allow the detailed independent reconstruction of } \\
\text { accidents }^{45}\end{array}$ & $\begin{array}{l}\text { Usually ineffective, }{ }^{46} \text { with reconstruction of incidents rarely } \\
\text { possible, }{ }^{47} \text { and 'black boxes' culturally difficult to employ. }{ }^{48} \text { Only } \\
\text { the most tragic of events are investigated independently }{ }^{49}\end{array}$ \\
\hline
\end{tabular}

Healthcare examples ${ }^{30}$

often poorly maintained, with significant gaps in engineering for often pooty 35

Lack of standardisation, ${ }^{37}$ professional autonomy, differences between practice settings, and differing prioritisations of behaviours and institutional protocols, ${ }^{38}$ making task definition a challenge

Safety communications ${ }^{40}$ and tasks ${ }^{41}$ are highly variable and tasks can be intermittently performed ${ }^{41}$ rigorously establishing which skills are essential or even for evaluating the degree to which these skills have been successfully acquired ${ }^{43}$

possible, ${ }^{47}$ and 'black boxes' culturally difficult to employ. ${ }^{48}$ Only the most tragic of events are investigated independently ${ }^{4}$ 
design. As a result, the benefits of CRM training in healthcare can be mixed. ${ }^{27} 28$

While CRM courses in aviation were supported by a huge volume of other HF expertise and infrastructure at every level of that highly engineered system, this has not been the case in healthcare (table 1). Maintaining a focus on behavioural change alone can result in a persistent blame-and-retrain mentality that may fit clinical and administrative models of risk management, and the enthusiasm to learn from aviation, but does not fix the underlying organisational, environmental, technological or task-related problems that also predispose to error. As a consequence, the 'human factor' has become frequently and erroneously used as a semantic surrogate for blame, the underlying problems are perpetuated, and the perception of HF degraded. Thus, despite its successes, the application of HF through behavioural safety training alone is a reflection of wider endemic systems problems in healthcare that not only disregards the basic concepts that high-quality HF practice should purport, but does a considerable disservice to clinicians, the HF profession, and efforts to improve safety.

\section{FROM HUMAN TO SYSTEM}

Healthcare differs from other high-tech industries in which HF has found more widespread application. The transport, defence and nuclear power industries are technology mediated, and have largely been engineered in the last 150 years to achieve specific goals. Healthcare still largely depends on direct human interventions and grew more organically over hundreds (even thousands) of years. It has many (sometimes conflicting) goals, from preserving life and relieving distress to a wide range of service qualities related to efficiency, and satisfaction with care and the care environment. It is arguably more complex than any other broadly equivalent industry, and is extremely resource sensitive, making the evidence base critical and the return on investment often difficult to gauge.

One can train staff about safety relatively easily (and possibly demonstrate some value thereof), but replacing equipment, redesigning complex processes, and addressing environmental limitations of hospital buildings present far greater challenges. It takes time to understand and resolve these issues. Moreover, investigating these deeper systems problems can be painful and expensive for all involved. This 'systems' view $^{50}$ ultimately challenges many concepts that clinical work is based on, such as the nature of evidence, ${ }^{51}$ the fallacy that good outcomes equate to good processes, ${ }^{52}$ and the fallacy of self-determinism, especially the view that errors cannot necessarily be avoided through force of will or more training. It can be disturbing for a clinical population who base their status, professional confidence and sometimes their business model on their individual abilities to realise how much their own performance is shaped by the equipment, tasks, environment and organisation around them. Human performance in healthcare systems is extremely complex, and the aviation CRM model alone-which does not address the level of individual, goal, task, evidential or conceptual complexity of clinical work-is insufficient to develop improved systems designs or better training.

The desire to use the broader range of HF principles poses a range of problems for funding, developing and using HF expertise. A relatively small number of qualified HF professionals work full time in healthcare anywhere in the world. Yet the expertise required to understand clinical complexities and conduct clinical HF improvement work requires considerable time and skill investment. HF positions in healthcare are far more elusive and transient than in every other hightech industry, with many HF activities funded through research. However, HF does not suit traditional medical research paradigms-they are often seen as 'soft' science-making it precarious to rely on research funding to support HF work. This situation sharply contrasts with that in aviation, for which there is clear commitment to and acknowledged value of the integration of HF professionals with engineering, safety, training, maintenance and service delivery teams. ${ }^{29}$

\section{FROM GATE KEEPERS OF KNOWLEDGE TO TRUSTED COLLEAGUES}

The speed with which HF ideas have spread in healthcare reflects recognition of the tremendous need for the application of HF expertise. Clearly, many of these issues are not solely problems that concern HF, but relate to wider questions about how good ideas can be spread and deepened without dilution or degradation. Given the complexity of healthcare systems, there is a coherent argument to say that the aviation approach has been the best place to start. It has built an excellent evidence base, has created a shift towards a system view, has spread the concept of HF (no matter how limited) and enabled immediate and successful intervention. So while the term 'HF' has been frequently misappropriated, the spread of reasoning based on these principles can lead to a properly systemic approach. However, the widespread adoption of only a limited set of principles, and the dominance of non-qualified practitioners in this area is a cause for concern. This is an impassioned topic on both sides of the boundaries of knowledge, and I have occasionally managed to upset clinical colleagues who have taken pride in their interpretation and delivery of HF training, and equally dedicated HF colleagues, who feel that this is misappropriation, a professional slur, and potentially dangerous to staff and patients. Addressing this discrepancy may be a unique challenge for the HF profession, while keeping HF only in the domain of qualified practitioners would be alienating and counter-productive. 
Clinical HF is different from HF in any other industry. If we wish healthcare to be fundamentally changed by HF, we must also expect HF to be changed by healthcare. Collaboration between clinicians and HF professionals, with each shaping the views of the other, will develop and extend the use of HF for the unique demands of healthcare. We need to develop accreditation for HF professionals working in healthcare, a greater presence of HF in the design of clinical systems and technologies, and in accident investigation and safety management, and we need to deliver training programmes in behavioural change and in system-level HF and appropriate analytical techniques. We also need an infrastructure that permanently supports that work, as has every other industry that has benefitted from HF.

Such developments will require a business model and a commitment to take this expertise forward. The Clinical HF Group (http://www.chfg.org) in the UK has made progress in attempting to address these issues, and has become influential and trusted precisely as it has arisen from the aviation model, but is now moving towards a wider definition, while involving all stakeholders in these challenging discussions. As this shift toward the deeper HF issues occurs, HF practitioners need to work across disciplinary boundaries to demonstrate and teach the value of what they can do. Then, we will be able to untangle these knots and appropriately use HF expertise to create better human-centred healthcare systems.

Funding Dr Catchpole receives funding from the US Department of Defence, Telemedicine and Advanced Technology Research Center grant W81XWH-10-1-1039, which seeks to reengineer teamwork and technology for twenty-first century trauma care.

Competing interests Dr Catchpole has published several papers on 'aviation style' human factors training and in the past received honoraria and consultancy fees for delivering lectures, training courses and analyses on this topic.

Provenance and peer review Commissioned; internally peer reviewed.

\section{REFERENCES}

1 Russ A, Fairbanks RJ, Karsh BT, et al. The science of human factors: separating fact from fiction. BMJ Qual Saf 2013.

2 Norris BJ. Systems human factors: how far have we come? BMJ Qual Saf 2011;21:713-14.

3 Gurses AP, Ozok AA, Pronovost PJ. Time to accelerate integration of human factors and ergonomics in patient safety. BMJ Qual Saf 2012;21:347-51.

4 Donaldson L. When will health care pass the orange-wire test? Lancet 2004;364:1567-8.

5 Leonard M, Graham S, Bonacum D. The human factor: the critical importance of effective teamwork and communication in providing safe care. Qual Saf Health Care 2004;13(Suppl 1):i85-90.

6 Wickens CD, Hollands JG. Engineering psychology and human performance. 3rd edn. Upper Saddle River, NJ: Prentice Hall, 2000.

7 Jankouskas T, Bush MC, Murray B, et al. Crisis resource management: evaluating outcomes of a multidisciplinary team. Simul Healthc 2007;2:96-101.
8 Haller G, Garnerin P, Morales MA, et al. Effect of crew resource management training in a multidisciplinary obstetrical setting. Int J Qual Health Care 2008;20:254-63.

9 Morey JC, Simon R, Jay GD, et al. Error reduction and performance improvement in the emergency department through formal teamwork training: evaluation results of the MedTeams project. Health Serv Res 2002;37:1553-81.

10 Grogan EL, Stiles RA, France DJ, et al. The impact of aviation-based teamwork training on the attitudes of health-care professionals. J Am Coll Surg 2004;199: 843-8.

11 Awad SS, Fagan SP, Bellows C, et al. Bridging the communication gap in the operating room with medical team training. Am J Surg 2005;190:770-4.

12 McCulloch P, Mishra A, Handa A, et al. The effects of aviation-style non-technical skills training on technical performance and outcome in the operating theatre. Qual Saf Health Care 2009;18:109-15.

13 Thomas EJ, Taggart B, Crandell S, et al. Teaching teamwork during the Neonatal Resuscitation Program: a randomized trial. J Perinatol 2007;27:409-14.

14 Halverson AL, Andersson JL, Anderson K, et al. Surgical team training: the Northwestern Memorial Hospital experience. Arch Surg 2009;144:107-12.

15 Ellis D, Crofts JF, Hunt LP, et al. Hospital, simulation center, and teamwork training for eclampsia management: a randomized controlled trial. Obstet Gynecol 2008;111:723-31.

16 Taylor CR, Hepworth JT, Buerhaus PI, et al. Effect of crew resource management on diabetes care and patient outcomes in an inner-city primary care clinic. Qual Saf Health Care 2007;16:244-7.

17 Nielsen PE, Goldman MB, Mann S, et al. Effects of teamwork training on adverse outcomes and process of care in labor and delivery: a randomized controlled trial. Obstet Gynecol 2007;109:48-55.

18 Barrett J, Gifford C, Morey J, et al. Enhancing patient safety through teamwork training. J Healthc Risk Manag 2001;21:57-65.

19 Yule S, Flin R, Maran N, et al. Surgeons' non-technical skills in the operating room: reliability testing of the NOTSS behavior rating system. World J Surg 2008;32:548-56.

20 Fletcher GCL, Flin RH, Glavin RJ, et al. Anaesthetists' Non-Technical Skills (ANTS): evaluation of a behavioural marker system. Br J Anaesth 2003;90:580-8.

21 Undre S, Sevdalis N, Healey AN, et al. Observational Teamwork Assessment for Surgery (OTAS): refinement and application in urological surgery. World J Surg 2007;31:1373-81.

22 Mitchell L, Flin R. Non-technical skills of the operating theatre scrub nurse: literature review. J Adv Nurs 2008;63:15-24.

23 MacDonald R, Waring J, Harrison S, et al. An ethnographic study of threats to patient safety in the operating theatre, 2005 http://www.pcpoh.bham.ac.uk/publichealth/psrp/ PS008_Project_Summary.shtml (accessed 3 Apr 2013).

24 Rogers J. Have we gone too far in translating ideas from aviation to patient safety? Yes. BMJ 2011;342:c7309.

25 Gaba DM. Have we gone too far in translating ideas from aviation to patient safety? No. BMJ 2011;342:c7310.

26 Norman DA. The design of everyday things. 1st Basic paperback. New York: Basic Books, 2002.

27 McCulloch P, Rathbone J, Catchpole K. Interventions to improve teamwork and communications among healthcare staff. Br J Surg 2011;98:469-79. 
28 Catchpole KR, Dale TJ, Hirst DG, et al. A multicenter trial of aviation-style training for surgical teams. J Patient Saf 2010;6:180-6.

29 Graeber C. The role of human factors in improving aviation safety. http://www.boeing.com/commercial/aeromagazine/ aero_08/human.html (accessed 3 Apr 2013).

30 Karl RC. Aviation. J Gastrointest Surg 2009;13:6-8.

31 Jarrett D. Cockpit engineering. Farnham: Ashgate Publishing, 2005.

32 Cutler V, Paddock S. Use of threat image projection (TIP) to enhance security performance, 2009. http://ieeexplore.ieee.org/ lpdocs $/$ epic03 $/$ wrapper.htm? arnumber $=5335565$ (accessed 27 Feb 2013).

33 Fairbanks RJ, Caplan SH, Bishop PA, et al. Usability study of two common defibrillators reveals hazards. Ann Emerg Med 2007;50:424-32.

34 Way LW, Stewart L, Gantert W, et al. Causes and prevention of laparoscopic bile duct injuries: analysis of 252 cases from a human factors and cognitive psychology perspective. Ann Surg 2003;237:460-9.

35 Magrabi F, Aarts J, Nohr C, et al. A comparative review of patient safety initiatives for national health information technology. Int J Med Inform 2012 Published Online First: 18 December 2012 doi:10.1016/j.ijmedinf.2012.11.014

36 Hutchins E. How a cockpit remembers its speeds. Cogn Sci 1995;19:265-88.

37 Burnett S, Franklin BD, Moorthy K, et al. How reliable are clinical systems in the UK NHS? A study of seven NHS organisations. BMJ Qual Saf 2012;21:466-72.

38 Welch WP, Miller ME, Welch HG, et al. Geographic variation in expenditures for physicians' services in the United States. N Engl J Med 1993;328:621-7.

39 Harris D. Human factors for civil flight deck design. Farnham: Ashgate Publishing, 2004.

40 Catchpole KR. Task, team and technology integration in the paediatric cardiac operating room. Prog Pediatr Cardiol 2011;32:85-8.
41 Poon SJ, Zuckerman SL, Mainthia R, et al. Methodology and bias in assessing compliance with a surgical safety checklist. Jt Comm J Qual Patient Saf 2013;39:77-82.

42 Carretta TR. U.S. Air Force pilot selection and training methods. Aviat Space Environ Med 2000;71: 950-6.

43 Gofton WT, Dudek NL, Wood TJ, et al. The Ottawa Surgical Competency Operating Room Evaluation (O-SCORE): a tool to assess surgical competence. Acad Med 2012;87:1401-7.

44 O’Leary M, Chappell SL. Confidential incident reporting systems create vital awareness of safety problems. ICAO J 1996;51:11-3, 27.

45 Suddath C. A brief history of black boxes. Time. http://www. time.com/time/nation/article/0,8599,1908245,00.html (accessed 5 Apr 2013).

46 Shojania KG. The frustrating case of incident-reporting systems. Qual Saf Health Care 2008;17:400-2.

47 Cone SW, Leung A, Mora F, et al. Multimedia data capture and management for surgical events: evaluation of a system. Telemed J E Health 2006;12:351-8.

48 Catchpole K, Godden PJ, Giddings AEB, et al. Identifying and reducing errors in the operating theatre. Patient Safety Research Programme, 2005. http://pcpoh.bham.ac.uk/publichealth/psrp/ publications.htm (accessed 3 Apr 2013).

49 Mid Staffordshire NHS Foundation Trust, UK. Report of the Mid Staffordshire NHS Foundation Trust public inquiry: executive summary. London: Stationery Office, 2010.

50 Reason J. Managing the risks of organisational accidents. Aldershot: Ashgate, 1997.

51 Smith GCS. Parachute use to prevent death and major trauma related to gravitational challenge: systematic review of randomised controlled trials. $B M J$ 2003;327:1459-61.

52 Dekker SW. The field guide to human error investigations. Aldershot: Ashgate, 2002. 